\section{Depressive Symptoms and Risk of Occupational and Non-occupational Injury in the US Working Population}

Jaeyoung Kim*

Department of Preventive Medicine, College of Medicine, Keimyung University, Korea

"Corresponding author: Jaeyoung Kim, Keimyung University, 1095, Dalgubeoldaero, Dalseo-gu, Daegu, Seoul 704-701, Korea, Tel: +82-53-580-3889; Fax: +82-53-580-3899; E-mail: jaeykim@dsmc.or.kr

Received date: March 25, 2015, Accepted date: May 26, 2015, Published date: May 30, 2015

Copyright: (c) $2015 \mathrm{Kim} \mathrm{J}$. This is an open-access article distributed under the terms of the Creative Commons Attribution License, which permits unrestricted use, distribution, and reproduction in any medium, provided the original author and source are credited.

\begin{abstract}
The purpose of this study was to examine the association between depressive symptoms and the subsequent incidence of injury by its work-relatedness in the US working population. This study analysed pooled panel data from the Medical Expenditure Panel Survey (MEPS) for 31,138 workers, aged 18 to 64 years, during the years 2000-06. Depressive symptoms were assessed using the EuroQoL (EQ-5D), a general mental distress scale (K-6) and Patients Health Questionnaire 2 item depression screener (PHQ-2). Injuries were identified from the medical conditions captured in personal interviews and coded using the ICD-9 by coders trained in the MEPS. A discrete time proportional odds model was used to calculate the relative risks. A total of $7.9 \%$ of workers had depressive symptoms at the baseline. Among workers with depressive symptoms at baseline, $13.1 \%$ reported a nonoccupational injury, $6.2 \%$ reported an occupational injury during follow-up. Workers with depressive symptoms are at an increased, but a similar risk of both occupational and non-occupational injury. For workers treated with antidepressants, the analysis did not reveal a different pattern of association with either type of injury occurrence. This association between depressive symptoms and injury diminished over time. Earlier intervention for workers with depressive symptoms in the workplace could be beneficial for preventing injuries.
\end{abstract}

Keywords: Depression; Depressive symptoms; Occupational injury; Non-occupational injury; Risk factors; Workers; MEPS

\section{Introduction}

Depression adversely impacts working life, leading to a greater likelihood of absenteeism, productivity loss, higher disability and unemployment $[1,2]$. Studies investigating the association between depression and injuries have mainly focused on either depression with unintentional injuries among the elderly in a given community or people in rural areas [3-5], or psychotropic medication use and the risk of injury among a community sample or hospital patients [6-9]. A few studies examined the relationship between depressive symptoms or psychosocial job stress and workplace injury [10-12]. Clearly, the role of depression in the risk of traumatic injury among the working population has not been explored thoroughly.

Depression may predict traumatic, unintentional injury either independently or through the established risk factors for an injury. Symptoms of depression such as fatigue and loss of interest may predispose an individual to a higher risk of traumatic injury $[5,13]$. The side effects of treatment for depression can impair cognitive function and may increase the likelihood of accidents $[7,14,15]$. Depression and injury may share common risk factors $[12,16]$. However, it is not yet clear whether the major causative factor is depression itself or the use of medication, or whether these factors are mediated through third factors such as drinking or smoking. Most study samples were limited to a group of elderly or patients in hospitals $[3,6,9,14,15]$, their results cannot be generalized in working population. In addition, their cross-sectional study design prohibited investigators from addressing temporality $[8,10,14,17]$.
A few studies have addressed temporality, by ensuring that depressive symptoms existed before the injury occurred [10,17]; however, their conclusions are also limited by small samples in local areas. Furthermore, the scope of such studies has not differentiated occupational and non-occupational injury. The current study examined the differential risk of occupational and non-occupational injury occurrence by depression using a nationally representative panel survey. The objective of this study was to what extent does baseline depression increase the risk of injury at follow-up and whether the magnitude of the injury risk differ by the workrelatedness of the injury with ensuring temporality. A better understanding of whether depression has a differential impact on injury depending on its work-relatedness will provide evidence for prioritizing intervention for depression and injury prevention.

\section{Materials and Methods}

\section{Study population}

Data were extracted from the 2000-06 Medical Expenditure Panel Survey (MEPS), a nationally representative household survey of the US population. Participants report on their health care utilization and health conditions. Information on each condition is recorded verbatim and later coded by professional coders into appropriate ICD-9 codes. The Agency for Healthcare Research and Quality (AHRQ) conducts five times in-person interviews over four- to five-month intervals; each group of five interviews constitutes one panel. Each panel starts in January of a given year and continues over two and a half years. The overall response rate across panels has generally ranged from $65 \%$ to $71 \%[18]$ 


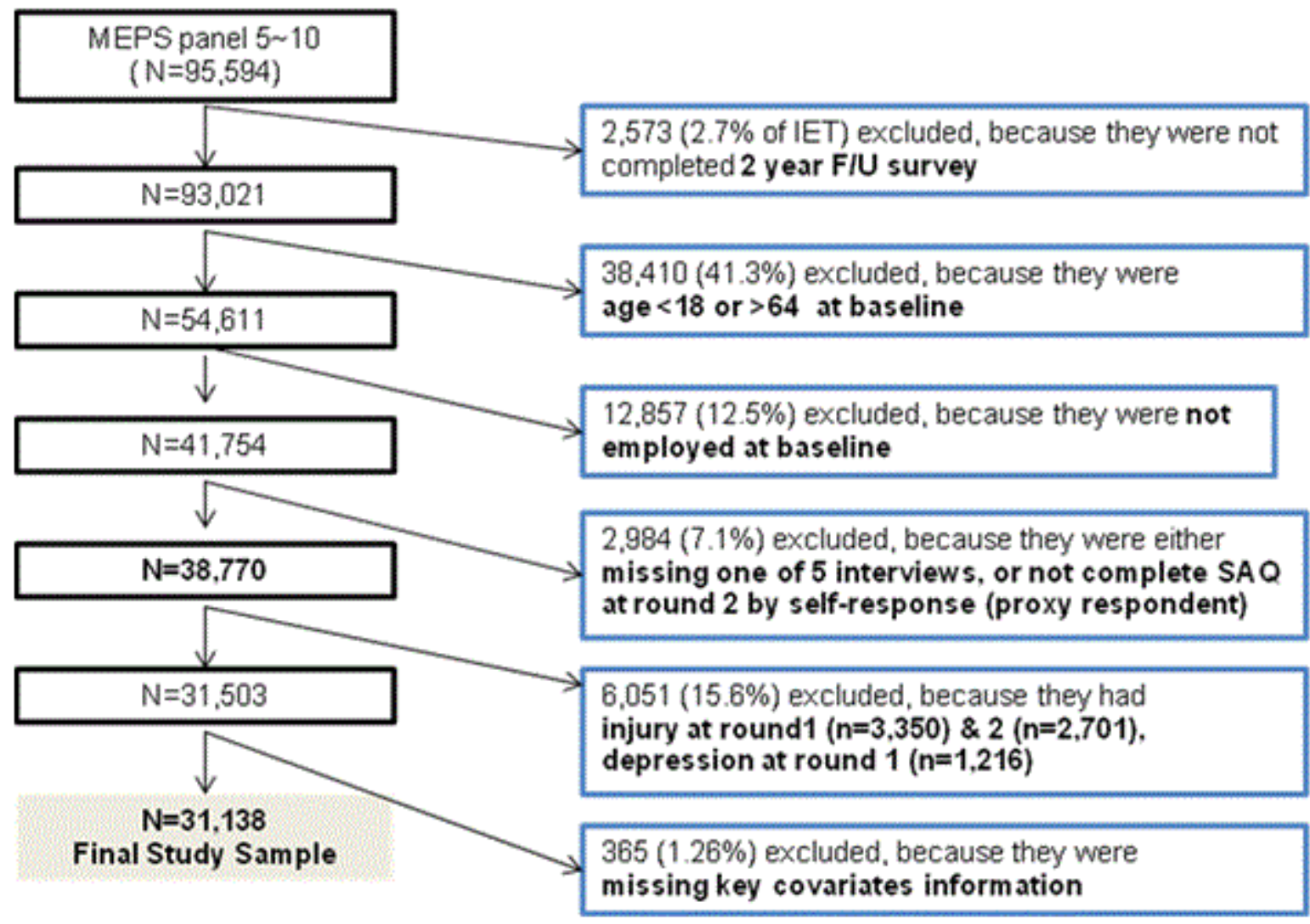

Figure 1: Selection process used to determine the final study sample

The final study sample was determined by a series of exclusions, as illustrated in Figure 1. Household respondents' files for each interview round were merged with files on medical conditions and job information to create a longitudinal panel. From six constructed MEPS panels, in which Panel 5 began interviews in 2000 and Panel 10 finished its interviews in 2006, an initial eligible total (IET) of 95,994 respondents were extracted. Round 2 interviews were designated as baseline because Round 1 interview information was used as an indicator for a previous history of depression, injury, or other comorbidity.

Individuals were excluded from the sample if they met any of the following criteria: 1) they did not complete the two-year survey in each panel due to death, departure from the U.S., institutionalization or military service ( $n=2,573 ; 2.7 \%$ of IET); 2 ) they were not eligible for all five rounds $(\mathrm{n}=706) ; 3)$ they were proxy interviews $(\mathrm{n}=148) ; 4)$ they were aged under 18 or over $65(n=38,410) ; 5)$ they were unemployed at baseline $(\mathrm{n}=12,857) ; 6)$ they did not complete the self-administered questionnaire (SAQ) by themselves, so the information about depressive symptoms was not available $(n=2,984)$; or 7$)$ data on key covariates was missing $(n=365)$. Finally, to ensure the temporal relationship between depression and injury, and to reduce the possibility that injury would affect the likelihood of depression in the following rounds, respondents who reported an injury at Round 1 and 2 and depression at Round $1(n=6,051)$ were excluded. The final analytic sample was 31,138 .

\section{Measures}

The primary predictors in this study were depressive symptoms and depression at baseline (Round 2). Depressive symptoms were measured using three tests: depression/anxiety domain of the EuroQoL (EQ-5D); K-6, a general mental distress scale; and the Patients Health Questionnaire (PHQ-2), 2-item depression screener. Because the MEPS began including the K- 6 scales and the PHQ-2 in 2004, a binary indicator of self-reported depressive symptoms was constructed using EQ-5D at panels 5 to 8, and the K-6 and PHQ-2 for panels 9 and 10. The cutoff point used for indicating depressive symptoms is at 3 in the EQ-5D, at 13 in the K-6, and of 3 in the PHQ-2, based on optimal cutoff points for screening purposes [19-21]. To check the validity and consistency of each measure across panels, a Mental Health Component Summary (MCS) of the Short Form Health Survey (SF-12) was used.

Depression was identified using two ICD-9 codes: 296.2 (major depression, single episode) and 311 (depressive disorder, NEC). The ICD-9 is the International Classification of Disease, 9th Revision, and the Clinical Modification. For each depression reported at the specific round, corresponding information regarding the health care were used, such as prescribed anti-depressants, hospital inpatient services, ambulatory services and emergency rooms visits. The analysis was confined to the first occurrence of a depression episode for each respondent across five rounds. A proxy was derived for depression severity from respondents' individual perceptions of the impact of the 
Page 3 of 9

depression on their overall health as 'very serious.' Depression severity was determined using the number of missed workdays due to depression, the number of treatment episodes and the duration of depression. A binary indicator of health care utilization was constructed related to depression using information on whether the person reported any depression-related medication and any depression-related ambulatory visits to clinics, outpatient departments or emergency rooms.

The main outcome variable in this study was incidents of injury in rounds 3 to 5; information retrieved from medical condition files in which individuals responded that "the medical condition they experienced during the four or five months since the previous interview" was due to an accident or injury. If the injury happened while the person was at work, it was identified as an occupational injury at the specific round. ICD-9 codes of injury condition were used to categorize the injured body region and type of injury based on the Barell classification matrix [22]. Injury severity was calculated using the Abbreviated Injury Scale (AIS) with ICD-9 codes and the selfperceived overall health impact of the injury [23]. Only the first injury in each round was selected to differentiate it from continuing treatment for an injury condition in the previous round. When respondents reported multiple, but different, injury conditions within one round, the most severe injury was chosen. Multiple injury episodes per person, number of health care utilizations and treatment duration for each injury condition were calculated.

Based on the risk factors reported in the literature, of depression, injury, or both $[11,24,25]$, five types of covariates were considered as potential confounders in the analysis: sociodemographic variables (age, gender, race, education, marital status, family income level), jobrelated (occupation, company size, self-employed), medical (comorbidity, activity limitation, perceived impact on overall health, number of health care events per condition), health behavior (current smoker, alcohol or substance abuse problem) and access to health care (insurance coverage, regularly visiting a particular doctor or health center). Information about medical condition and employment was collected in all rounds, but questions about health behavior were asked at round $2 / 4$ or $3 / 5$. At each round, when available, the covariates were updated if changes in them could alter the association between occupational injury and depression.

\section{Data analysis}

The characteristics of respondents with and without depressive symptoms were summarized using raw frequencies and weighted percentages. A chi-squared test was used to compare the distributions of major demographic characteristics and work-related variables between depressive workers. Cause of injury, diagnosis, severity, lost work day, number of injury episodes and treatment duration by depression were reported. A discrete time-proportional odds model [26] was used to estimate the likelihood of injury occurrence during rounds 3 through 5 compared to baseline depression. A discrete-time logistic model with multinomial indicators of occupational and nonoccupational injury occurrence was fitted to a logistic regression model. The final model was built using the goodness-of-fit test developed by Hosmer et al. [27]. This yielded set included depression, age, gender, race, education, occupation, income, marital status, no usual source of health care, alcohol or substance abuse disorder, current smoking, obesity, exercise, activity limitation, cognitive function impairment, co-morbidity, perceived physical and mental health status, job tenure, working hours per week, full time work, injury severity, and injury time since depression. Using the final model, the analysis was repeated for workers who reported taking a prescribed anti-depressant. Then an additional stratified analysis for potential moderators was conducted including time, depression treatment, and occupation. All analyses were performed using SAS 9.2. An association between an exposure and outcome was declared statistically significant at $\mathrm{p}<0.05$.

\section{Ethics statement}

This study was exempt under category 4 (research of existing data publicly available) by the Harvard School of Public Health Human Subjects Committee (IRB).

\section{Results}

\section{Demographic characteristics}

Selected demographic characteristics of the study populations have been summarized at baseline with and without depressive symptoms (Table 1). Workers with depressive symptoms were more likely to be female and white, with lower levels of family income, and less access to health care than those who had no depressive symptoms. Depressed individuals showed less healthy personal behaviors including less exercise, more current smoking and more obesity. Their physical and mental health status at baseline was less positive, with work, school and social activities tending to be limited due to medical conditions and cognitive impairments. Co-morbidity levels were also higher in depressed workers. A greater proportion of workers with a depressive symptoms worked part-time, had less than one year of job tenure, and were more likely to work at service occupations (all $\mathrm{p}<0.01$ ). Among workers with depressive symptoms at baseline, a total of $6.2 \%(n=85)$ reported an occupational injury, $13.1 \%(\mathrm{n}=179)$ reported nonoccupational injury at the follow-up time.

\begin{tabular}{|c|c|c|}
\hline Characteristics $^{a}$ & No depressive symptoms Number (\%) & Depressive symptoms Number (\%) \\
\hline Total & $29,772(100)$ & $1,366(100)$ \\
\hline \multicolumn{3}{|l|}{ Gender $(\%)^{*}$} \\
\hline Women & $14,412(48.4)$ & $883(64.6)$ \\
\hline Mean age (years) & 39.1(11.9) & $38.4(11.7)$ \\
\hline \multicolumn{3}{|l|}{ Race } \\
\hline White & $20,961(70.4)$ & $994(72.7)$ \\
\hline
\end{tabular}


Citation: Kim J (2015) Depressive Symptoms and Risk of Occupational and Non-occupational Injury in the US Working Population. Occup Med Health Aff 3: 200. doi:10.4172/2329-6879.1000200

Page 4 of 9

\begin{tabular}{|c|c|c|}
\hline Black & $3,770(12.7)$ & $148(10.8)$ \\
\hline \multicolumn{3}{|l|}{ Education* } \\
\hline Less than high school & $6,914(23.2)$ & $340(24.9)$ \\
\hline High school graduate & $8,828(29.7)$ & $410(30.0)$ \\
\hline Some college & $6,764(22.7)$ & $347(25.4)$ \\
\hline College or more & $7,266(24.4)$ & $269(19.7)$ \\
\hline \multicolumn{3}{|l|}{ Marital status* } \\
\hline Married & $18,014(60.5)$ & $655(48.0)$ \\
\hline Never married & $7,689(25.8)$ & $403(29.5)$ \\
\hline Divorced, widowed, separated & $4,069(13.7)$ & $308(22.5)$ \\
\hline \multicolumn{3}{|l|}{ Family income $t^{*}$} \\
\hline Low $(<125 \% \mathrm{FPL})$ & $3,947(13.3)$ & $273(20.0)$ \\
\hline Middle (125-399\% FPL) & $14,293(48.0)$ & $660(48.3)$ \\
\hline High ( $\geq 400 \%$ FPL ) & $11,532(38.7)$ & $433(31.7)$ \\
\hline No usual source of health care ${ }^{*}$ & $8,780(29.5)$ & $335(24.5)$ \\
\hline \multicolumn{3}{|l|}{ Health insurance coverage* } \\
\hline Any private & $22,674(75.2)$ & $938(68.7)$ \\
\hline Public only & $1,678(5.6)$ & $134(9.8)$ \\
\hline Uninsured & $5,720(19.2)$ & $294(22.5)$ \\
\hline Physical activity $\S^{*}$ & $17,092(57.4)$ & $679(49.7)$ \\
\hline Current smoking $\|^{*}$ & $5,921(19.9)$ & $452(33.1)$ \\
\hline Alcohol or substance abuse problem & $33(0.1)$ & $5(0.4)$ \\
\hline Obese $(B M I \geq 30)^{*}$ & $7,819(26.3)$ & $436(31.9)$ \\
\hline Activity limitation ${ }_{\mathrm{T}}^{*}$ & $357(1.2)$ & $72(5.3)$ \\
\hline Cognitive function limitation $\pi$ & $222(0.8)$ & $59(4.3)$ \\
\hline Co-morbidity $\Pi^{\star}$ & $1,024(3.4)$ & $85(6.2)$ \\
\hline Self-rated physical health: Poor ${ }^{*}$ & $220(0.7)$ & $68(5.0)$ \\
\hline Self-rated mental health: Poor ${ }^{*}$ & $670(2.3)$ & $343(25.1)$ \\
\hline \multicolumn{3}{|l|}{ Occupational group* } \\
\hline White collar & $16,161(54.3)$ & $767(56.2)$ \\
\hline Service & $5,120(17.2)$ & $288(21.1)$ \\
\hline Farm & $324(1.1)$ & $13(1.0)$ \\
\hline Blue collar & $7,722(25.9)$ & $283(20.7)$ \\
\hline \multicolumn{3}{|l|}{ Job tenure ${ }^{*}$} \\
\hline Less than 1 year & $10,357(34.8)$ & $637(46.6)$ \\
\hline More than 5 years & $12,451(41.8)$ & $429(31.4)$ \\
\hline
\end{tabular}


Citation: Kim J (2015) Depressive Symptoms and Risk of Occupational and Non-occupational Injury in the US Working Population. Occup Med Health Aff 3: 200. doi:10.4172/2329-6879.1000200

Page 6 of 9

\begin{tabular}{|l|l|l|}
\hline Minor (ISS 1 8) & $209(51.5)$ & $98(39.5)$ \\
\hline Moderate (ISS 9 15) & $1217(31.2)$ & $78(31.5)$ \\
\hline Severe (ISS $\geq 16)$ & $672(17.2)$ & $72(29.0)$ \\
\hline Injury treatment duration & \multicolumn{2}{|l|}{} \\
\hline More than one round & $555(14.2)$ & $52(21.0)$ \\
\hline Lost work days & \multicolumn{2}{|l|}{} \\
\hline More than one day & $1515(38.9)$ & $95(38.3)$ \\
\hline No. injury episodes & & \\
\hline Multiple & $1167(29.9)$ & $77(31.1)$ \\
\hline * $p<0.05$ & \multicolumn{2}{|l|}{} \\
\hline
\end{tabular}

Table 2: Distribution of traumatic injuries (\%) in the 4,144 injured works in the study population by depression and injury characteristics.

\section{Multivariate analyses}

Workers with depressive symptoms had higher odds of injury, which were very similar for both non-occupational and occupational injuries (Table 3). The adjusted odds of non-occupational injury and occupational injury were 1.33 (95\% CI: $1.13,1.57)$ and 1.37 (95\% CI: $1.08,1.70)$, respectively. Final model explained $32.7 \%$ of non- occupational injury risk and $27.5 \%$ of occupational injury risk for workers with depressive symptoms. Impaired cognitive function was highly associated with the risk of non-occupational injury among depressive workers, whereas occupation was independently associated with higher odds of occupational injury.

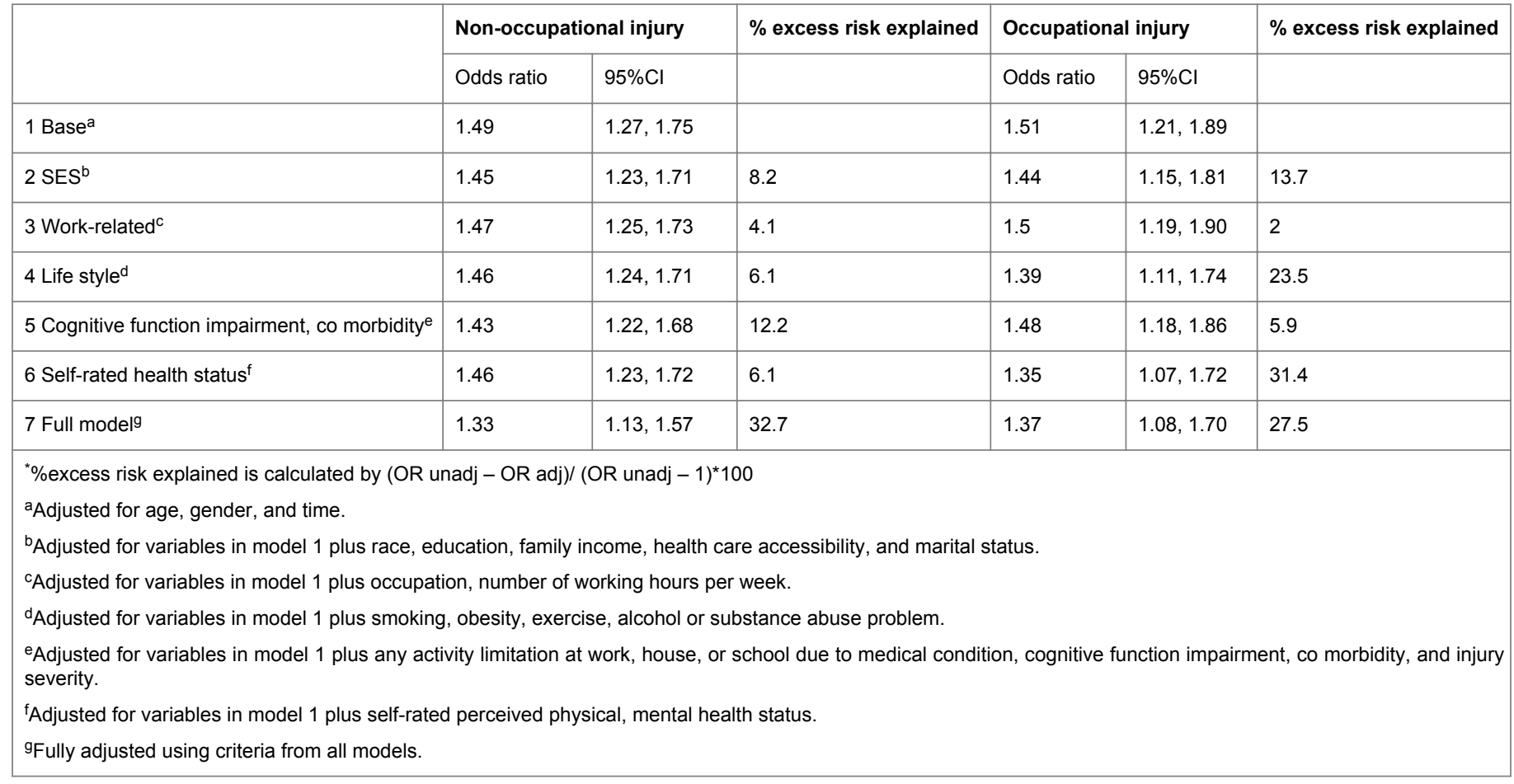

Table 3: Contribution of risk factors to the association between depressive symptoms and injuries in 31,138 workers in MEPS, $2000-2006$.

The pattern of association showing similarly increased odds of nonoccupational and occupational injury was observed in most of the stratified results (Table 4). Taking antidepressants showed similar magnitude of increased likelihood of both non-occupational and occupational injury. The occupation-specific odds for non- occupational injury were highest among blue-collar workers, whereas depressed workers in white-collar occupations had the highest odds of occupational injuries. Higher odds of injuries for those with depressive symptoms were more apparent in shorter time intervals between depressive symptoms and injury occurrence. 


\begin{tabular}{|c|c|c|c|c|}
\hline \multirow[t]{2}{*}{ Characteristics } & \multicolumn{2}{|c|}{ Non-occupational injury $(n=2,892)$} & \multicolumn{2}{|c|}{ Occupational injury $(n=1,440)$} \\
\hline & Adjusted OR & $95 \% \mathrm{Cl}$ & Adjusted OR & $95 \% \mathrm{Cl}$ \\
\hline \multicolumn{5}{|c|}{ Injury time since the depressiont } \\
\hline Less than 1 round & 1.00 & & 1.00 & \\
\hline 1 round & 1.45 & $1.15,1.76$ & 1.49 & $1.06,2.10$ \\
\hline 2 rounds & 1.25 & $0.97,1.58$ & 1.42 & $1.01,2.02$ \\
\hline 3 rounds & 1.29 & $0.94,1.79$ & 0.98 & $0.59,1.53$ \\
\hline \multicolumn{5}{|c|}{ Antidepressant medication } \\
\hline No & 1.00 & & 1.00 & \\
\hline Yes & 1.62 & $1.13,2.32$ & 1.18 & $0.85,2.14$ \\
\hline \multicolumn{5}{|c|}{ Duration of depression } \\
\hline Less than 1 round & 1.00 & & 1.00 & \\
\hline More than 1 round & 1.14 & $0.63,1.99$ & 0.83 & $0.36,1.95$ \\
\hline \multicolumn{5}{|l|}{ Occupational group } \\
\hline Farm & 1.00 & & 1.00 & \\
\hline White collar & 1.17 & $0.94,1.45$ & 1.82 & $1.32,2.49$ \\
\hline Service & 1.37 & $0.96,1.95$ & 1.26 & $0.78,2.04$ \\
\hline Blue collar & 1.90 & $1.34,2.66$ & 0.97 & $0.61,1.53$ \\
\hline \multicolumn{5}{|l|}{${ }^{*} p<0.05$} \\
\hline
\end{tabular}

Table 4: Adjusted odds of injury occurrence by depressive symptoms among 31,138 workers from MEPS panels 5-10, with multivariate-adjusted models stratified by time, anti-depressant medication, duration of depression, and occupation.

\section{Discussion}

The association between baseline depressive symptoms and subsequent occupational and non-occupational injury were examined among U.S. employees aged 18 to 64 years using a nationally representative sample. This study found that depressive symptoms were associated with higher odds of injury occurrence, and that the magnitude of the association for non-occupational or occupational injury was similar, suggesting that depressive symptoms have no differential impact on the work-relatedness of injury occurrence. Impairment in cognitive function was highly associated with the risk of non-occupational injury. The higher likelihood of injury among depressed workers was also associated with several covariates: male gender, unmarried status (divorced, separated, or widowed), low personal wage income, lower level of education, less health care accessibility, current smoking and obesity. Adjusting these covariates did not substantially attenuate the association between depressive symptoms and injury risk, suggesting that depressive symptoms are an independent risk factor for injury occurrence among the working population. The odds that those with depressive symptoms would become injured were higher at shorter time intervals and were no longer significant one year after the follow-up.
The limitations of this study could be a lack of detailed job descriptions and information on stressful life events outside the workplace, potential recall bias, and attrition in the MEPS. First, the MEPS lacked data on several potential confounding variables including family history, other stressful life events outside the workplace, detailed job descriptions and psychosocial conditions in the workplace. The lack of data limited the ability of this analysis to explore the mechanism between depressive symptoms and injury occurrence. Second, information in the MEPS was self-reported and thus may introduce recall bias, a characteristic of many other studies using population survey data. However, the interval between rounds was relatively short, at five to six months. Further, the self-reported medical conditions in the MEPS were verified by the Medical Provider Component (MPC), supplemental survey of respondents' medical providers and pharmacies. The error rate for coding medical conditions based on ICD-9 codes was reported as not exceeding $2.5 \%$ on verification. Therefore, it is unlikely that these results were biased by self-reporting of medical conditions on the MEPS. Finally, attrition in the MEPS may not be random and thus could lead to bias. While the initial response rate of MEPS was over $85 \%, 30 \%$ of respondents were lost by the fifth round. The AHRQ, however, reported it had no evidence of potential non-response bias attributable to survey attrition on resultant national estimates of health care cost [28]. In this study, 
the $95 \%$ confidence intervals for the non-significant associations were relatively wide; therefore, caution should be used in interpreting the non-significant results.

Even considering such limitations, this study differs from previous research in several ways: longitudinal design, a nationally representative sample of the working population, a focus on the differential impact of occupational injury, an ability both to differentiate pre-existing depression and PTSD from post-injury depression, and to control for co-morbidity and injury severity. First, by using longitudinal data and by excluding cases at baseline with preexisting depression among the injured group, this study was able to establish the temporality of the association between injury and depression. Second, by using a representative sample of the working population, more general conclusions become plausible. The MEPS is a self-reported survey, but data on exposure and outcome were retrieved for all medical conditions, separate from the respondents' awareness. This approach may avoid the risk of circular reasoning, while guaranteeing that exposure and outcomes were measured independently. Fourth, using the information for all medically treated or related health conditions, for co-morbidity and other psychiatric conditions were adjusted that are associated with increased risk of depression or injury. Co-morbid conditions and physical disability are well-known risk factors for depression as well as injury. By dealing with such conditions adequately, the potential bias in the risk estimate from reverse causality was reduced.

Findings of this study are consistent with previous studies that suggest an elevated risk of traumatic injury for persons with depressive symptoms. In this study, depressive symptoms were associated with 1.3 times higher odds of non-occupational and occupational injury among the working population over one and half years of follow-up. It added some evidence for positive association to the somewhat mixed findings of previous research. Several prospective studies support my results, having found a relationship between depressive symptoms and increased risk of unintentional injury in rural community [3], and higher prevalence for occupational injury among depressed female workers [12,17]. Antidepressant use was associated with accidents both at work and outside work [7,8,14]. Several studies report differential risks of depression among occupational groups by addressing the job attributes related to depression [29-31]. The nonoccupational injury risk for depressive workers appeared to be largely accounted for by limitations on cognitive function. In contrast, the effects that depressive symptoms have on the risk of occupational injury depend mainly on the type of occupation: those in white-collar occupations with depressive symptoms showed significantly increased risks of occupational injury, and those in blue-collar occupations had higher risks of non-occupational injury. These findings suggest that type of occupation may alter the risk of injury among those who are depressed.

Depressive symptoms have been documented as a common psychological factor related to the occurrence of accidental injury $[4,11,32]$. In this study, taking anti-depressant and longer duration of depression were positively associated with the risk of nonoccupational injury, although some of them did not reach the statistical significance. The pathway from depression to injury is not established, but two mechanisms have been suggested. First, depression may predict traumatic injury independently. Depressive symptoms such as impaired cognitive function, fatigue or difficulty concentrating, may come from depression itself or may be the side effects of anti-depressants [6-9]. Especially, impairments in cognitive function have been pointed out as a potential cause of injury; along with other risk factors they may predispose an individual to a higher risk of unintentional injury [9]. Similarly, this study observed that cognitive function impairment is a major risk factor in the association between depressive symptoms and injury occurrence, particularly as those with symptoms have two times the odds of getting nonoccupational injuries compared to those without symptoms. Second, depression may operate through established risk factors for an injury. Some of the individual behaviors related to depression may also be related to behaviors that may cause an injury. Higher levels of smoking, drinking, obesity and physical inactivity may be exacerbated by depression, and may subsequently mediate the risk of injury. This finding could not identify the specific psychosocial working conditions that may have created an increased risk of injury or depression in this study, but this study found that cognitive function impairment was the strongest predictor in the association between depressive symptoms and injury occurrence. A positive association was found between other risk factors such as marital status, smoking, obesity, occupation and injury occurrence. Given these findings, it seems likely that depressive symptoms or a shared risk factor could be a potential explanatory mechanism of injury in this study.

Nonetheless, adjustments for socioeconomic variables, personal health behavior or baseline health condition did not substantially attenuate the associations. This finding suggests that depressive symptoms in themselves are an independent risk factor for injury occurrence, rather than being mediated by other risk factors. The stronger association observed in the shorter follow-up time suggests that the impact of depressive symptoms on injury occurrence may be transient, rather than being cumulative or long-lasting.

\section{Conclusion}

In summary, depressive symptoms in the working population were associated with an increased risk of traumatic injury. The magnitude of the association was similar to non-occupational and occupational injury, yet stronger in the risk of both injuries within a short time interval. These results suggest that depression does not lead to an equal risk of occupational injury for workers on all job types, reflected in the risk of occupation-specific injury. These findings can have practical implications in addressing the need for early intervention and effective depression management in the workplace by understanding the role of depression as a risk factor for a traumatic injury among working population. Policy makers in the fields of occupational health and safety should consider the potential impact of depressive symptoms, and also note the need for intervention policies to reduce the social burden of depression as well as to benefit work productivity.

\section{Conflict of Interest}

The authors declare no conflict of interest.

\section{References}

1. De Graaf R, Tuithof M, Van Dorsselaer S, ten Have M (2012) Comparing the effects on work performance of mental and physical disorders. Soc Psychiatry Psychiatr Epidemiol 47: 1873-1883.

2. Kessler RC (2012) The costs of depression. Psychiatr Clin North Am 35: 1-14.

3. Fragar L, Inder KJ, Kelly BJ, Coleman C, Perkins D, et al. (2013) Unintentional injury, psychological distress and depressive symptoms: is there an association for rural Australians? J Rural Health 29: 12-19. 
Citation: Kim J (2015) Depressive Symptoms and Risk of Occupational and Non-occupational Injury in the US Working Population. Occup Med Health Aff 3: 200. doi:10.4172/2329-6879.1000200

Page 9 of 9

4. Kvelde T, Lord SR, Close JC, Reppermund S, Kochan NA, et al. (2015) Depressive symptoms increase fall risk in older people, independent of antidepressant use, and reduced executive and physical functioning. Arch Gerontol Geriatr 60: 190-195.

5. Connorton E, Miller M, Perry MJ, Hemenway D (2011) Mental health and unintentional injurers: results from the national co-morbidity survey replication. Inj Prev 17: 171-175.

6. Mattila V, Pelkonen M, Henriksson M, Marttunen M (2008) Injury risk in young psychiatric outpatients: an 11-year follow-up of 302 adolescents Soc Psychiatry Psychiatr Epidemiol 43: 627-634.

7. Palmer KT, D'angelo S, Harris EC, Linaker C, Coggon D (2014) The role of mental health problems and common psychotropic drug treatments in accidental injury at work: a case-control study. Occup Environ Med 71 308-312.

8. Vestergaard P, Prieto-Alhambra D, Javaid MK, Cooper C (2013) Fractures in users of antidepressants and anxiolytics and sedatives: effects of age and dose. Osteoporos Int 24: 671-680.

9. Gale CR, Dennison EM, Edwards M, Sayer AA, Cooper C (2012) Symptoms of anxiety or depression and risk of fracture in older people: the Hertfordshire Cohort Study. Arch Osteoporos 7: 59-65.

10. Kim HC, Park SG, Min KB, Yoon KJ (2009) Depressive symptoms and self-reported occupational injury in small and medium-sized companies. Int Arch Occup Environ Health 82: 715-721.

11. Palmer KT, Harris EC, Coggon D (2008) Chronic health problems and risk of accidental injury in the workplace: a systematic literature review. Occup Environ Med 65: 757-764.

12. Patten SB, Williams JV, Lavorato DH, Eliasziw M (2010) Major depression and injury risk. Can J Psychiatry 55: 313-318.

13. Dewa CS (2007) Mental Illness and the Workplace: A National Concern. Canadian Journal of Psychiatry 52: 337-338.

14. Wadsworth EJ, Moss SC, Simpson SA, Smith AP (2005) Psychotropic medication use and accidents, injuries and cognitive failures. Human Psycho pharmmcology-clinical and experimental 20: 391-400.

15. Quach L, Yang FM, Berry SD, Newton E, Jones RN, et al. (2013) Depression, antidepressants, and falls among community-dwelling elderly people: the MOBILIZE Boston study. J Gerontol A Biol Sci Med Sci 68: 1575-1581.

16. Biderman A, Cwikel J, Fried AV, Galinsky D (2002) Depression and falls among community dwelling elderly people: a search for common risk factors. J Epidemiol Community Health 56: 631-636.

17. Peele PB, Tollerud DJ (2005) Depression and Occupational Injury: Results of a Pilot Investigation. J Occup Environ Med 47: 424-427.

18. Ezzati-Rice T, Rohde F, Greenblatt J (2008) Sample Design of the Medical Expenditure Panel Survey Household Component, 1998 - 2007.
Methodology Report No. 22. Agency for Healthcare Research and Quality, Rockville, MD.

19. Kessler RC, Andrews G, Colpe LJ, Hiripi E, Mroczek DK, et al. (2002) Short screening scales to monitor population prevalences and trends in non-specific psychological distress. Psychol Med 32: 959-976.

20. Kroenke K, Spitzer RL, Williams JB (2003) The Patient Health Questionnaire-2: validity of a two-item depression screener. Med Care 41: 1284-1292.

21. Dolan P (1997) Modeling valuations for EuroQol health states. Med Care pp. 1095-1108.

22. Barell V, Aharonson-Daniel L, Fingerhut L, Mackenzie E, Ziv A, et al. (2002) An introduction to the Barell body region by nature of injury diagnosis matrix. Inj Prev 8: 91-96.

23. Greenspan L, Mclellan B, Greig H (1985) Abbreviated injury scale and injury severity score: a scoring chart. The Journal of trauma 25: 60-64.

24. Bonde JP (2008) Psychosocial factors at work and risk of depression: a systematic review of the epidemiological evidence. Br Med J 65: 438-445.

25. Brattstrom O, Eriksson M, Larsson E, Oldner A (2014) Socio-economic status and co-morbidity as risk factors for trauma. Eur J Epidemiol 30: 151-157.

26. Willett JB, Singer JD (2004) Discrete-time survival analysis. Kaplan D, The sage handbook of quantitative methodology for the social sciences, Madison.

27. Hosmer DW, Lemeshow S, Wiley J, Interscience W (2000) Applied logistic regression.

28. Cohen SB, Ezzati-Rice T, Yu W (2006) The impact of survey attrition on health insurance coverage estimates in a National Longitudinal Health Care Survey. Health Services and Outcomes Research Methodology 6: 111-125.

29. Zimmerman FJ, Christakis DA, Vander Stoep A (2004) Tinker, tailor, soldier, patient: work attributes and depression disparities among young adults. Soc Sci Med 58: 1889-1901.

30. Stansfeld SA, Rasul FR, Head J, Singleton N (2011) Occupation and mental health in a national UK survey. Soc Psychiatry Psychiatr Epidemiol 46: 101-110.

31. Marchand A, Drapeau A, Beaulieu-Prevost D (2012) Psychological distress in Canada: the role of employment and reasons of nonemployment. Int J Soc Psychiatry 58: 596-604.

32. Tiesman HM, Peek-Asa C, Whitten P, Sprince NL, Stromquist A, et al. (2006) Depressive symptoms as a risk factor for unintentional injury: a cohort study in a rural county. Inj Prev 12: 172-177. 